\title{
Robert Boyle's Weather Journal for the Year 1685
}

\author{
Richard C. Cornes ${ }^{1 *}$ \\ ${ }^{1}$ National Oceanography Centre, Southampton, UK \\ ${ }^{*}$ Corresponding author: richard.cornes@noc.ac.uk
}

\begin{abstract}
Robert Boyle was one of the most influential natural philosophers of the Enlightenment. Although he recorded fragmentary instrumental meteorological readings in his numerous works, it was generally thought that he did not record observations with the regularity seen with other late-seventeenth century philosophers. However, in the Boyle archive at the Royal Society in London is a diary that was recorded while Boyle was living in London and which provides a largely complete record of twice-daily barometer, thermometer and weather readings from December 1684 to January 1686. As far as I can tell these data have not been converted to modern units or scrutinized in any systematic manner. In this paper I derive corrections for the instrumental observations, and examine the weather descriptions. Although the record is short it does provide a detailed daily snapshot of weather conditions for this 14-month period around London. The enduring feature of the weather during the year 1685 were the dry conditions that lasted into early summer. The journal indicates that the winter $1684-5$ was cold and frequent frosts and fog were experienced, although the following winter of $1685-6$ was relatively mild; summer 1685 appears to have been relatively cool. Overall, the data attest to the variety of weather conditions that could be experienced in London during the Late Maunder Minimum.
\end{abstract}

Keywords: Little Ice Age, Robert Hooke, barometer, Royal Society, Drought 


\section{Introduction}

Robert Boyle (1627-1691, Figure 1) was one of the most influential figures of the Enlightenment. As the youngest son of the Earl of Cork, Boyle was born into the aristocracy and following his Grand Tour of the continent in the 1640s he became engaged in the new natural philosophy that was developing at the time (Hunter, 2000). By the 1660s Boyle was well established, and was a central character in the scientific institutions that were forming in Oxford and London, including the Royal Society, of which he was a founding member. Boyle was a prolific author, publishing on a range of subjects, notably chemistry and theology, but perhaps his most famous achievement were the air pump experiments, which he conducted with Robert Hooke in the early 1660s, and which paved the way for the formulation of his eponymous fundamental gas law (Shaw, 1920). In connection with these experiments, Boyle and Hooke made improvements to the design of the barometer (Crewe, 2003). Indeed Boyle was the first person to propose the term 'barometer' as an alternative to 'baroscope', which was in general use in the late seventeenth century (Knowles Middleton, 1964).

In an age when instruments and scales often varied from observer-to-observer, Boyle recognized the need for systematic record-keeping using standardized meteorological instruments, and of comparing observations from different locations (Birch, 1756; Gunther, 1923). In the inaugural volume of the Philosophical Transactions of the Royal Society, Boyle (1665a) had provided directions for maintaining a consistent record using a barometer, and in his letter to Samuel Hartlib, published posthumously in 1692, he further advocated the keeping of instrumental weather diaries, writing "I would have no man, who hath leisure, opportunity and time, to think it a slight thing to busy himself in collecting observations of this nature" (Boyle, 1692, p. 77). This encouragement came as part of a wider initiative by members of the Royal Society to construct a "natural history of meteors" (Jankovic, 2001; Golinski, 2007), and while Boyle was not unique in his support of systematic record-keeping, his eminent status in the scientific community certainly added weight to the argument.

As early as 1659 or 1660 Boyle was recording pressure observations in Oxford using a mercury barometer but these are only fragmentary records, and while there are several other references to instrumental observations in his many works, it was generally assumed that despite his support for the effort, Boyle did not record weather observations with the regularity 
seen in the journals of other late-seventeenth century philosophers such as John Locke, William Derham or Richard Towneley (Manley, 1963; Folland and Wales-Smith, 1977; Slonosky et al., 2001; Cornes et al., 2012a). However, contained in the archive of Boyle's papers at the Royal Society in London is a tabular weather diary for the period December 1684 to January 1686 that was kept while Boyle was living in London. The diary provides a largely complete record of twice-daily barometer, thermometer and weather readings over the 14 month period, but as far as I can tell the instrumental observations have not previously been corrected to modern units or scrutinized in any systematic manner.

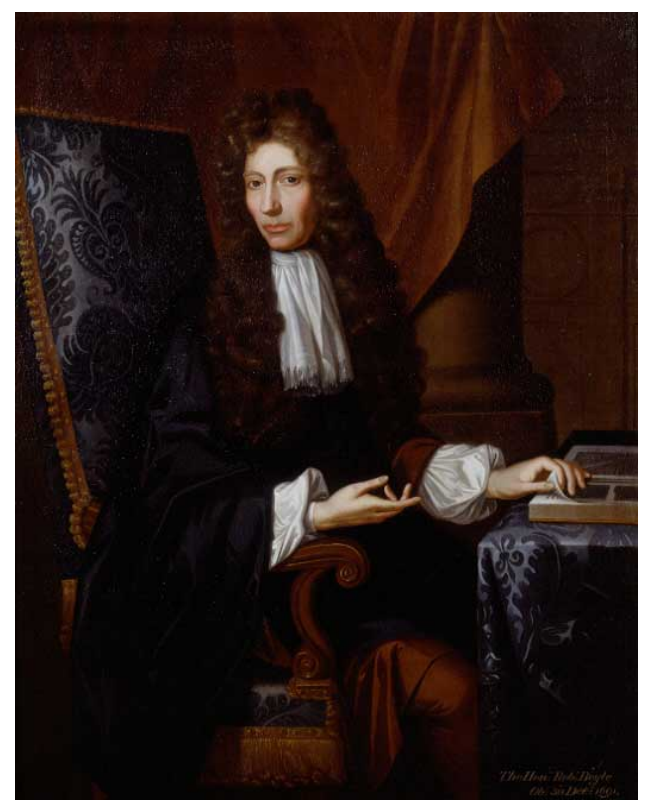

Figure 1: A portrait of Boyle made by Johann Kerseboom in 1689 and is hence broadly contemporary to the weather diary (see Hunter, 2009).

\section{Provenance of the Weather Journal}

The weather journal ${ }^{1}$ is small $(16 \times 10 \mathrm{~cm}$, with 21 double-sided leaves, see Figure 2$)$ and is bound in a commonplace book as part of the collection that contains Boyle's notebooks and manuscripts (Hunter and Davis, 2007). The journal consists of a table of instrumental observations, taken mostly at $8 \mathrm{am}$ and $10 \mathrm{pm}$, followed by a description of the day's weather, which summarizes the daytime and nighttime weather conditions. Interestingly, although Boyle had proposed the term 'barometer', the readings are headed 'baroscope' in the journal, and provide further evidence that the two terms were used interchangeably (Knowles Middleton, 1964).

\footnotetext{
${ }^{1}$ MS 190, fols. 146-66 (ref no. RB/2/21/11) Royal Society Archive, London.
} 


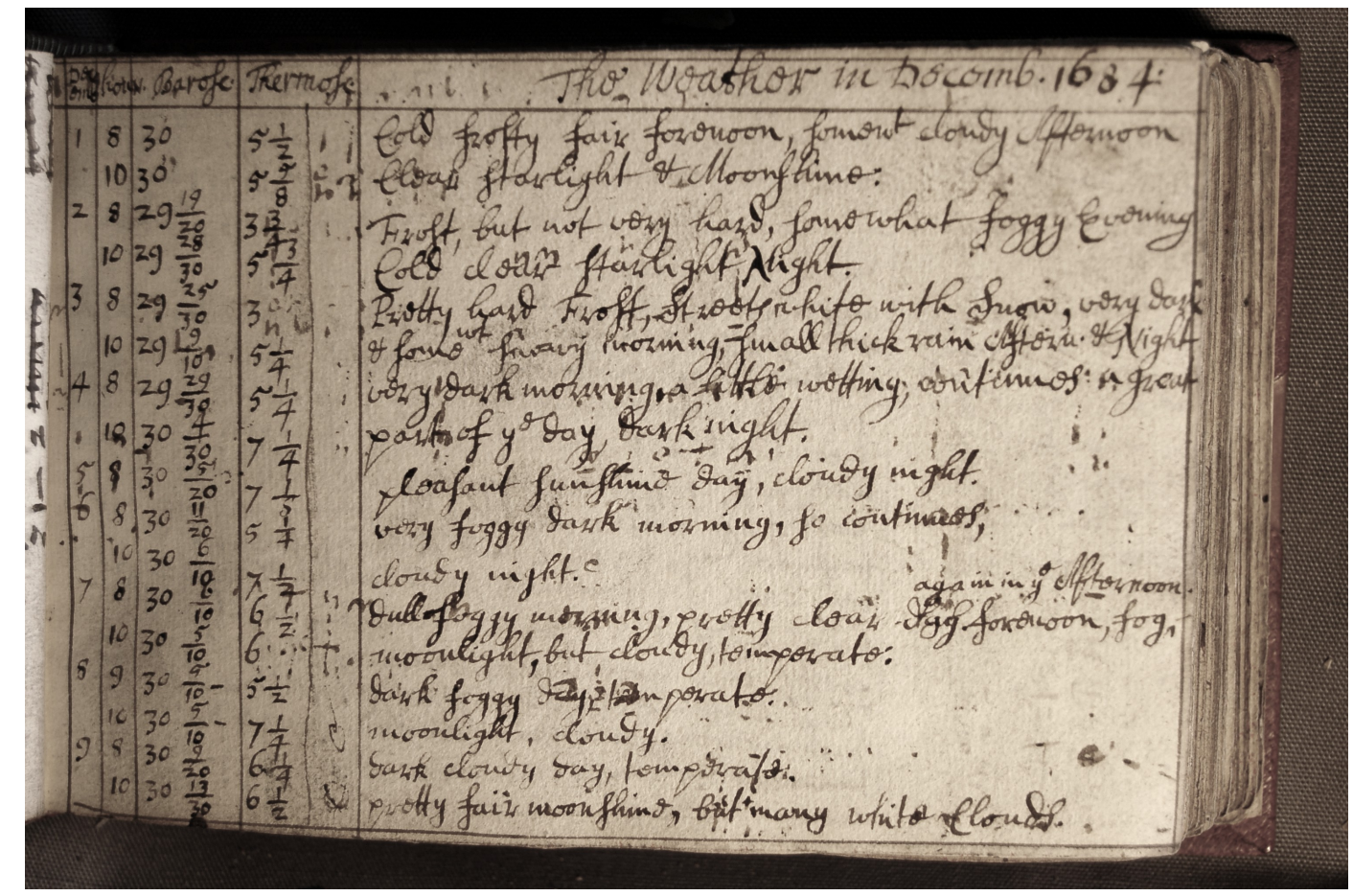

Figure 2: The first page of the weather journal showing the observations for 1-9th December 1684 (O.S.). Reproduced by courtesy of The Royal Society.

An analysis of the handwriting by Hunter and Davis (2007) revealed that the journal was written by Boyle's assistant Hugh Greg. This is to be expected as most of Boyle's experimental work and particularly the observations were recorded by assistants, of whom he employed several at a time; some of these assistants remained working for him for many years. Certain assistants, such as Hugh Greg, were responsible for setting-up experiments, recording observations and also fulfilled a servant-type role; others, and most notably Robert Hooke, assumed the role of apprentice, learning the skills of scientific research before embarking on scientific careers of their own. In this way Boyle's method of working was rather like a modern laboratory (Hall, 1958), and while other scientists at the time worked in a similar manner, it was certainly only possible for the most eminent of scientists who also had the funds to support such an enterprise. For Boyle the practicalities of large-scale experimental work along with his poor eyesight — which affected him from a young age — necessitated this organisation, and towards the end of his life when these readings were taken he was less concerned with the day-to-day experimental work as a result of deteriorating health and especially worsening eyesight (Maddison, 1969).

The weather observations were taken when Boyle was living in London. Boyle had moved 
to London from Oxford in 1668 to live permanently with his sister Katherine, Lady Ranelagh, at a relatively new residence in Pall Mall (today 89-91 Pall Mall) (Shapin, 1988). At the basement or back of the house Boyle had a private laboratory built, and while no details exist for the laboratory it was probably similar in form if not scale to that depicted in Figure 3 (Maddison, 1955). It was in this laboratory that most of Boyle's experiments were made.

The language used to describe the day's weather and the types of events recorded are similar to many Restoration-period English weather diaries, with descriptions of the severity of frost, the degree of fog and the occurrence of snow or rainfall noted. The descriptions are, however, perhaps more detailed than many contemporary diaries. The weather description contains diligent observations of the degree of cloud cover at night and the occurrence of starlight or moonlight, the absence of which is often denoted by the adjective "dark". The journal also contains entries relating to moon phases. Notably, on 21/12/1684 (New Style Calendar, N.S. ${ }^{2}$ ) "a long eclipse of the moon" was recorded; this can be independently verified using modern calculations (see http://eclipse.gsf c.nasa.gov/lunar.html). These observations were likely made to verify the old theory that celestial bodies had an influence on the weather (Jankovic, 2001; Golinski, 2007).

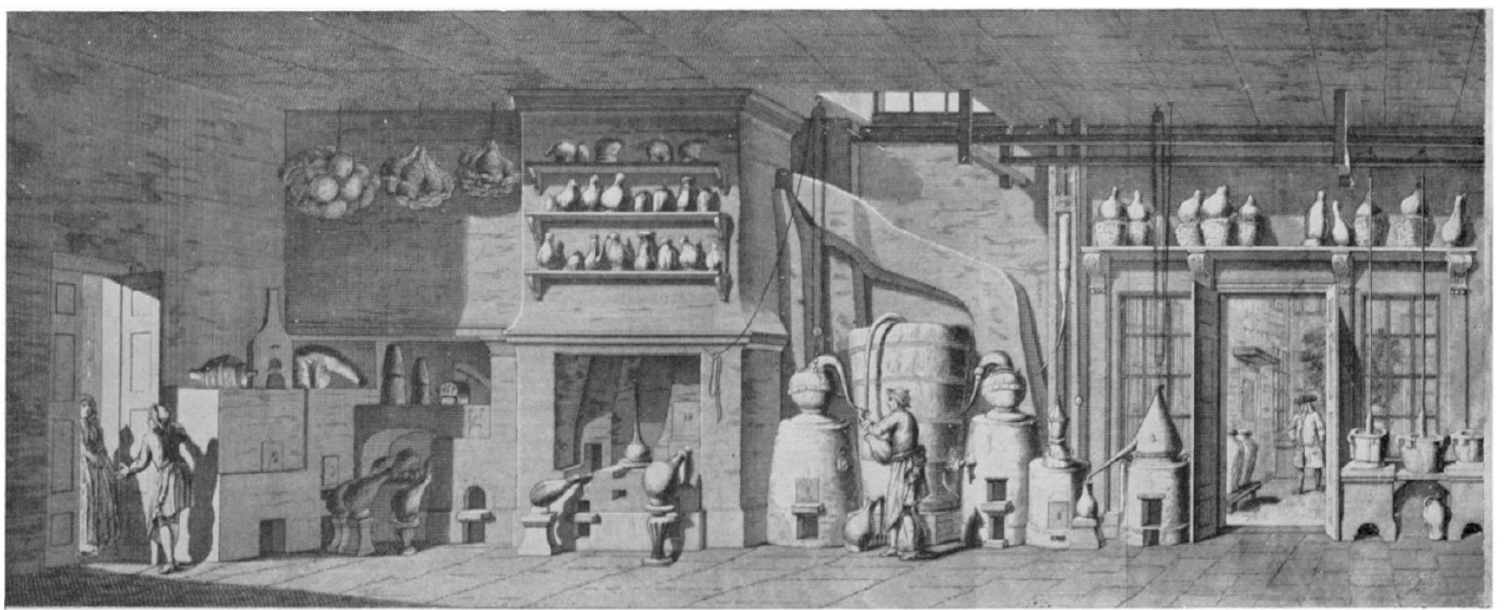

Figure 3: The laboratory of Ambrose Godfrey Hanckwitz, which dates to the late seventeenth century. Although this was the largest such laboratory at the time, it provides an indication of the layout of Restoration-period chemical laboratories. Hanckwitz was a former assistant of Boyle, and later had a laboratory built behind his house in the Golden Phoenix at Southampton Street for carrying out his own chemical experiments, probably in a similar style to Boyle's laboratory in Pall Mall. This laboratory has often been mistakenly called "Boyle's Laboratory" (see Maddison, 1955).

\footnotetext{
${ }^{2}$ Calendar dates in England prior to 1752 were recorded according to the Julian calendar. In addition the year began on Lady Day (25th March). I have corrected the dates as recorded in the diary from this Old Style (O.S.) reckoning to the New Style, Gregorian calendar (N.S.) by adding 10 days to the dates and referencing the start of year to the 1st January.
} 


\section{Corrections Applied to the Data}

\section{The Temperature Readings}

There is no information in the diary about the nature of the instrument used to record the temperature measurements, but it is likely that a Florentine thermometer was employed. The Florentine thermometer was developed in the mid-seventeenth century by the Accademia del Cimento in Italy (Camuffo and Bertolin, 2012a,b), and Boyle quickly recognized the importance of using these hermetically sealed thermometers, which prevented the undesirable influence of atmospheric pressure from affecting the temperature readings (Boyle, 1665b). Alcohol (spirit of wine) was used in the thermometers, and while Boyle had suggested that mercury might be a better substance, there is no evidence to suggest that such an instruments were available at the time (Knowles Middleton, 1966).

Robert Hooke constructed a number of Florentine thermometers to a common standard, and describes the process in Micrographia (Knowles Middleton, 1966). These instruments were 4 feet in length and the spirit was coloured with cochineal to give it a vivid crimson hue. The temperature scale used on these instruments marked zero as the freezing point of water and Patterson (1953) ascertained that one unit was equal to between $1.1^{\circ} \mathrm{C}$ and $1.2^{\circ}$ C. The scale appears to have been later doubled to one unit equal to $2.4^{\circ} \mathrm{C}$. This scale was widely adopted by members of the Royal Society, and became the de facto standard for many London practitioners. However, while Boyle (1665b) documents the use of the scale on his 'trusty sealed Thermoscope', this is not the scale used in the London weather journal, since the values range from $-51 / 2$ to $197 / 8$. Rather the instrument appears to have used Hooke's original finer scaling and I have corrected the temperature readings as one unit equal to $1.1^{\circ}$ C. However, a consistent warm bias of around $2.5^{\circ} \mathrm{C}$ remains in the values, when the monthly mean values (corrected for the limited diurnal sampling) are compared against Manley's (1961) monthly means values for London (Table 1). This bias is taken as a calibration offset and I have subtracted $2.5^{\circ} \mathrm{C}$ from the scaled values under this assumption. The total scale correction for the raw temperature values $(T)$ is hence $T^{\prime}=T \cdot 1.1-2.5$.

The location of the thermometer in recording these temperatures is not known. There is evidence that Boyle, as with many of his contemporaries, favoured keeping thermometers in unheated rooms near to a window (Patterson, 1953; Manley, 1961). On the whole, the 


\section{a) Temperature Observations}

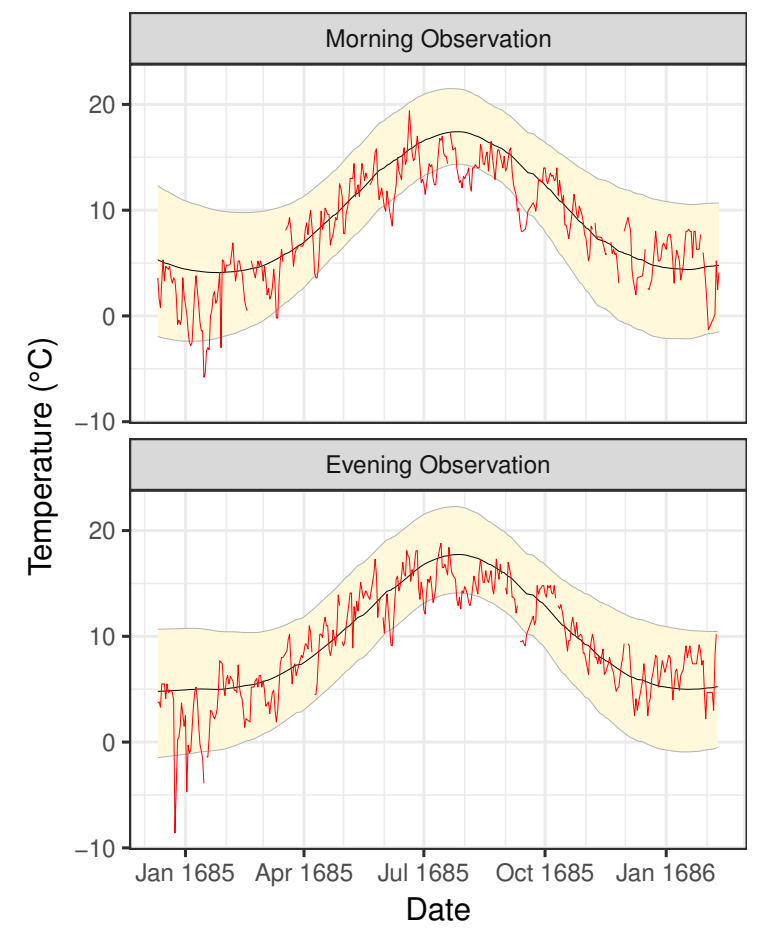

b) MSLP Observations

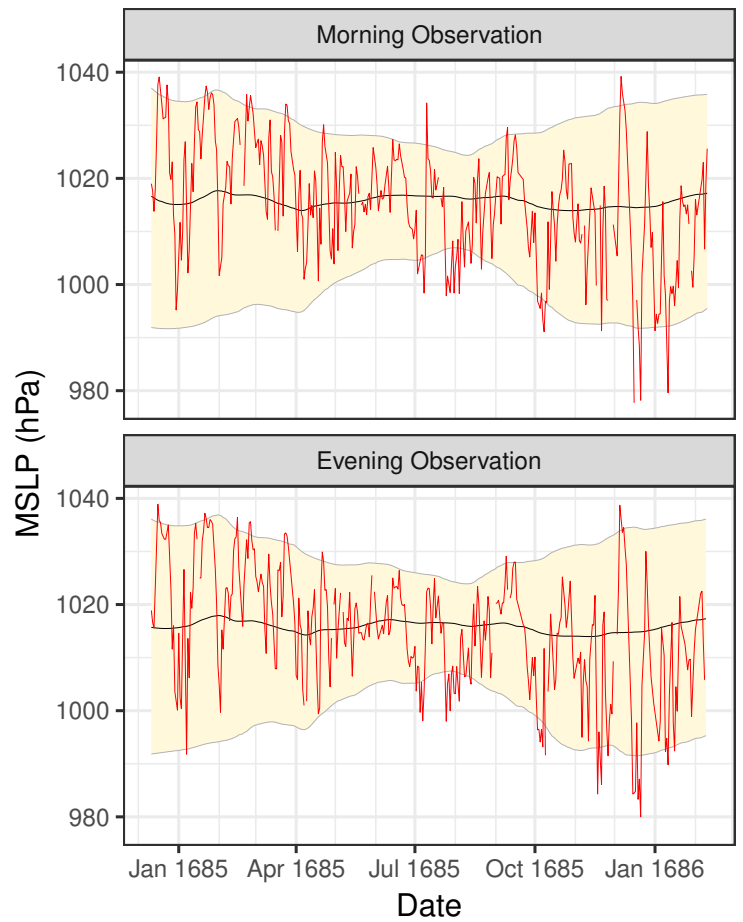

Figure 4: Boyle's corrected temperature and pressure readings compared against modern observations recorded at Heathrow airport. The shaded region indicates the 5-95th percentile range for the 19812010 period, and the black line indicates the mean over that period. These values have been smoothed with a loess filter, and use the 8UTC and 22UTC readings at Heathrow, which correspond to the observation times of Boyle's readings. 
relatively draughty nature of Restoration-period houses means that the error connected with the observations being recorded indoors is reduced compared to modern indoor observations (Manley, 1961), although the readings are likely lagged compared to outdoor readings and extremes may be suppressed (Bergström and Moberg, 2002). Indeed, on his standard thermometer graduated to the larger Royal Society Scale and used during his time in Oxford, Boyle recorded a difference of 2-2 1/8 units between his bedroom before a fire was heated and the temperature in his garden during a frost (Boyle, 1683). This can not explain the warm bias described above, which is consistent throughout the year, but may indicate that the values around zero may be too warm by around $2-5^{\circ} \mathrm{C}$ (Patterson, 1953). Since I can not be certain that this applies to the readings in the London weather diary, I have not applied a correction for this possible indoor-effect. Likewise it must be borne in mind that other factors probably affect these measurements, such as the use of spirit of wine for the thermometric medium and a potential unevenness of the glass tube (Camuffo and Jones, 2002; Camuffo and Bertolin, 2012b; Camuffo and Valle, 2016).

The corrected thermometer readings have been compared (Figure 4 a) against modern drybulb thermometer observations from Heathrow Airport and the contemporary temperature observations recorded by the French physician Louis Morin in Paris (Legrand and Le Goff, 1992) (Figure 6 a). Despite the inherent deficiencies in these ancient thermometer readings, the results indicate that Boyle's thermometer was a responsive instrument, capable of recording both day-to-day changes and also the annual cycle of temperature remarkably well. The monthly mean values are comparable to the independent estimations made by Manley (1961) for the London area (Table 1), although it should be stressed that the calibration error in Boyle's readings has been determined through comparison against Manley's estimates.

\section{The Barometric Pressure Readings}

The pressure observations recorded in the weather journal are of particular interest given Boyle's pioneering air pump experiments. The instrument used in the weather journal measured the height of mercury in English Inches but as with the thermometer nothing else is known about the instrument. Boyle wrote about experiments using both siphon and cistern barometers and describes a cistern-type instrument that he considered his reference, at least during the 1660s (Boyle, 1665b). It is also known that Robert Hooke developed a wheel- 
barometer for Boyle, although the scale used on that instrument was unique (Patterson, 1953) and this is clearly not the measurements we have in the weather journal. The measurements in the diary appear to have been recorded using a scale divided into 30ths of an inch, with the fractions simplified where appropriate to 10ths of an inch. It is known that Boyle used instruments constructed by one of London's finest instrument-makers Thomas Tompion (Goodison, 1977), and it is conceivable that the readings were taken using one of his barometers.

To correct the barometer measurements to modern-day standards the values were initially converted to the unit of $\mathrm{hPa}$. Corrections for thermal expansion of the mercury (i.e. to reduce the reading to the current standard of $0^{\circ} \mathrm{C}$ ) were achieved by using the concurrent thermometer readings converted to degrees Celsius. This reduced the values by around $-1 \mathrm{hPa}$ during the winter months and $-3 \mathrm{hPa}$ in the summer. The pressure values were then adjusted for the acceleration due to gravity (an addition of approximately $0.5 \mathrm{hPa}$ ) and altitude (an addition of $3 \mathrm{hPa}$ ). These latter corrections were made assuming a height of $25 \mathrm{~m}$, which is reasonable given the probable location of the instrument on the ground floor of the Pall Mall laboratory.

If Boyle had used a cistern-type barometer for these measurements, as seems likely, a correction is necessary to account for the varying height of the mercury in the cistern in relation to that in the tube (Knowles Middleton, 1964; Camuffo et al., 2010). To apply this correction, information is needed about the diameters of the barometer's cistern and tube, as well as the neutral point, at which the correction is zero. Unfortunately, we have none of these details. However, a contemporary publication from the late seventeenth century reports that Boyle's barometer had a small diameter tube in relation to other barometers in use at the time that had larger diameter tubes and which suppressed variations in the height of the mercury (Smith, 1688). The cistern-capacity error is therefore likely to be reduced compared to contemporary measurements made using less refined instruments.

Analysis of the barometer readings indicate a responsive instrument. The uncorrected readings are strongly correlated $(\mathrm{r}=0.96)$ with the comparable readings taken by Robert Plot at the Old Ashmolean Museum in Oxford during December 1684 (Plot, 1685) although there is an indication that Plot's barometer was susceptible to sticking (Figure 5). Further support for the quality of Boyle's readings is provided by the comparison of the pressure data against modern daily ranges (Figure 4 b) and Louis Morin's daily readings from Paris (Figure 6 b). An 
inhomogeneity exists in Morin's readings, which requires the application of an index-correction as after applying the usual corrections for temperature, gravity and altitude the readings are too low (Legrand and Le Goff, 1992; Slonosky et al., 2001; Cornes et al., 2012b). Following Camuffo et al. (2010), this correction is achieved by adding 5.5hPa to all values until October 1685. The comparison against Boyle's data indicate that this is a realistic correction.

\section{Weather Conditions During the Year}

Table 1: Monthly means (N.S. calendar) of temperature and pressure from Boyle's journal, and the temperature values estimated by Manley (1961) for London and the Central England Temperature (CET) series (Manley, 1974). February 1686 has been excluded are there are too few data to calculate reliable monthly values. The maximum and minimum values are simply indicate the range of values recorded across the month regardless of the time of observation. A correction for the limited diurnal sampling has been applied to the mean temperature values and amounts to a value of $+0.5^{\circ} \mathrm{C}$ in winter, up to $+1^{\circ} \mathrm{C}$ in summer.

\begin{tabular}{|c|c|c|c|c|c|c|c|c|}
\hline & & CET (degC) & London $(\operatorname{deg} C)$ & Mean $(\operatorname{deg} C)$ & Min $(\operatorname{deg} C)$ & $\operatorname{Max}(\operatorname{deg} C)$ & Mean (hPa) & Min \\
\hline 1684 & Dec & 4.0 & 4 & 3 & -9 & 6 & 1023 & \\
\hline \multirow[t]{12}{*}{1685} & Jan & 0.5 & 1 & 2 & -6 & 8 & 1024 & \\
\hline & Feb & 3.5 & 4 & 6 & 0 & 7 & 1024 & \\
\hline & Mar & 5.0 & 6 & 7 & -0 & 10 & 1023 & \\
\hline & Apr & 8.5 & 9 & 10 & 4 & 14 & 1014 & \\
\hline & May & 12.5 & 13 & 14 & 8 & 17 & 1017 & \\
\hline & Jun & 14.5 & 16 & 15 & 8 & 19 & 1018 & \\
\hline & Jul & 14.0 & 15 & 16 & 12 & 19 & 1011 & \\
\hline & Aug & 14.5 & 16 & 16 & 12 & 17 & 1012 & \\
\hline & Sep & 11.5 & 13 & 13 & 8 & 17 & 1018 & \\
\hline & Oct & 11.5 & 12 & 12 & 7 & 15 & 1010 & \\
\hline & Nov & 7.0 & 8 & 8 & 3 & 10 & 1005 & \\
\hline & Dec & 6.5 & 7 & 6 & 2 & 9 & 1010 & \\
\hline 1686 & Jan & 6.5 & 7 & 7 & 2 & 9 & 1004 & \\
\hline
\end{tabular}

The winter of 1683-4 remains the coldest in the Central England Temperature (CET) series (Manley, 1975) and we can speculate that in anticipation of a repeat of events Boyle initiated the keeping of a detailed record in December 1684 to document the conditions. The winter 1684-5 did indeed turn out to be very cold and dry, and prompted Sir John Wittewronge in his diary at Rothamsted in Hertfordshire to describe the season as "long and tiring" (Hughes, 1984; Stevenson et al., 1999); it did not, however, reach the severity experienced in the previous winter, although across central Europe the winter of $1684-5$ was likely more severe, with significant snow fall experienced (Lamb, 1995; Pfister, 1999; Glaser, 2013). The estimated temperatures from both Boyle's diary and Louis Morin's journal in Paris indicate a high 


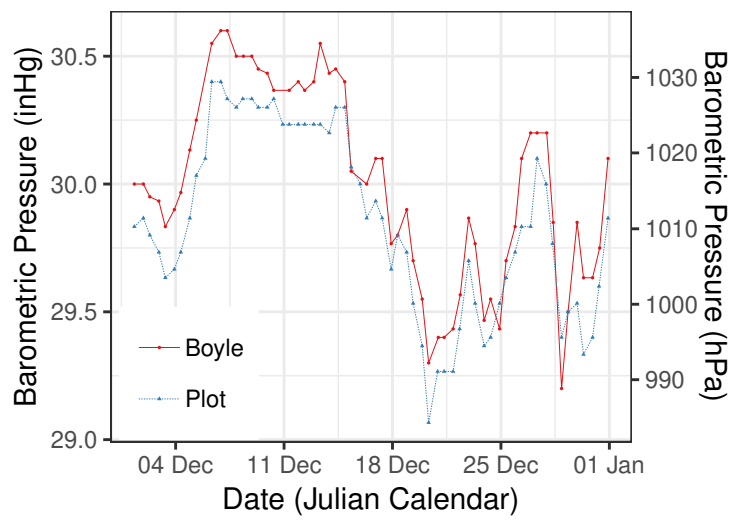

Figure 5: A comparison between Boyle's uncorrected pressure readings and and those recorded by Robert Plot at the Old Ashmolean Museum in Oxford during December 1684. The mean differences in the readings $(0.2 \mathrm{inHg})$ can largely be explained by the differences in altitude of the two locations (Boyle $-25 \mathrm{~m}$ and Plot - 70m). Plot's observations were taken from the barograms published in Plot (1685) and estimates were made of the morning and evening observations from that figure

\section{a) Temperature}

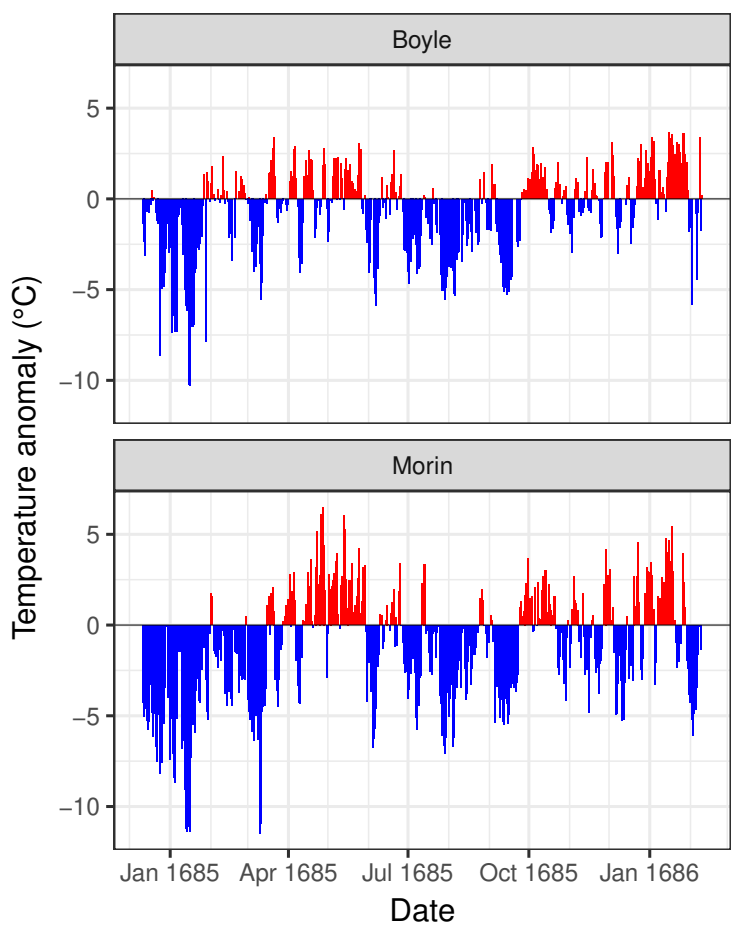

b) Sea-level Pressure

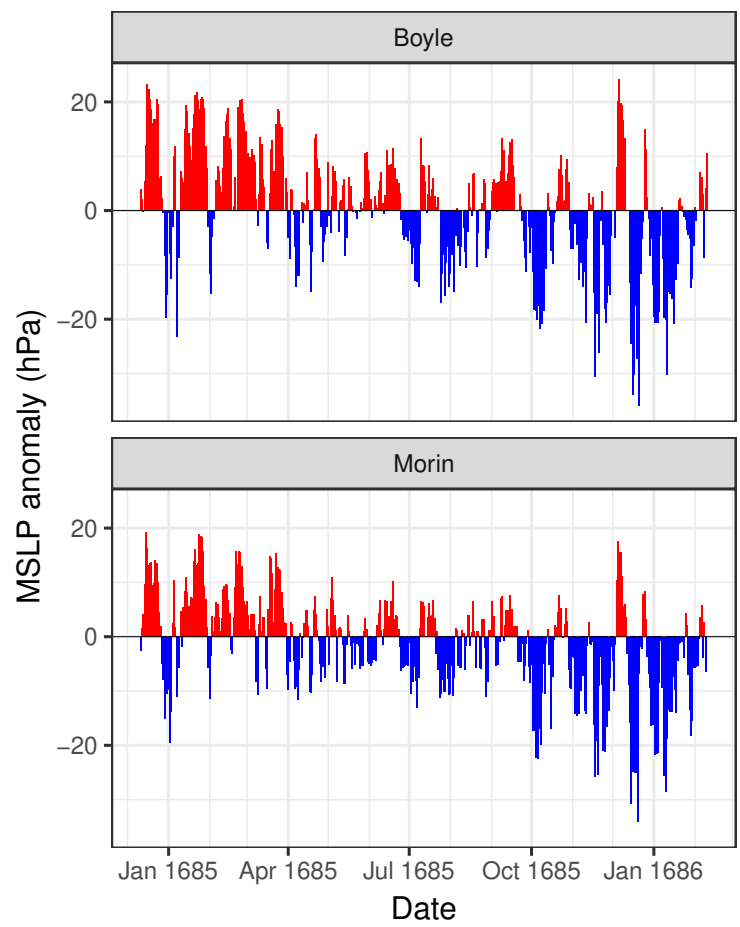

Figure 6: Daily mean temperature and MSLP values recorded by Boyle and Morin expressed as anomalies with respect to 1981-2010 averages from the Montsouris Observatory (Morin) and Heathrow Airport (Boyle). Morin's daily temperature values are calculated by Legrand \& Legoff's (1992) from their daily maximum and minimum estimates, and expressed here as anomalies from daily maximum and minimum values from the modern observations. Boyle's values are the average of the morning and evening readings and are expressed as anomalies from averages of the $8 \mathrm{UTC}$ and 22UTC readings from Heathrow Airport. 
degree of variability in temperatures (Figure 6), and we learn from John Evelyn's diary kept in London that the Thames often froze, melted and refroze throughout January; frosts were frequent throughout the season (Figure 8). The temperature anomalies seem to have been lower in Paris, but this may be related to the higher daily sampling of Louis Morin's readings, and the derivation of daily minima/maxima by Legrand and Le Goff (1987). A particularly severe cold snap occurred in London during the middle part of February arising from easterly winds, during which Boyle's diary describes the frosts as severe. According to Kington (2010), snowstorm-blizzard conditions were experienced around 2nd January. This accords well with Boyle's diary, which records some snow on the 1st January followed by very strong winds on the 2nd. Fog is recorded throughout the season, particularly in December 1684, with certain occurrences described as 'mighty thick'.

It is evident from a number of weather compilations and other documentary sources that the period from January until July was very dry, and that a drought affected the region (Pribyl and Cornes, 2019a,b). A comparison of the number of rain days recorded in Boyle's diary and those record by Louis Morin in Paris indicates these dry conditions. Very few rain days are recorded in Boyle's diary, particularly during the first four months of the year (Figure 8), with a total of 114 recorded for the year 1685; Legrand and Le Goff (1992) have calculated a total of 106 rain/snow days from Morin's weather diary, which was the second lowest total over the 1671-1709 period (the lowest number of 104 occurred in 1691). By comparison the average annual total of rain/snow days over that period stands at 141 days.

The blocked weather situation responsible for these conditions is evident in Boyle's corrected pressure readings, with monthly means in London generally above $1022 \mathrm{hPa}$ from December 1684 to March 1685 (Table 1), although dropping to below 1005hPa on two occasions (Figure 4 b). Similar pressure values were recorded in Paris by Louis Morin. Lamb (1995) suggested that while the conditions in winter 1683-4 were connected to a Greenland high pattern, a Scandinavian high pattern occurred in winter $1684-5$. The multi-proxy reconstruction of pressure fields by Luterbacher et al. (2002) provides further information about the atmospheric circulation pattern across Europe during these winters (Figure 7), although for the latter season it seems likely with the additional information provided by Boyle's observations - which are not used in the reconstruction - that the MSLP across southern England is slightly too low and that the central European high-pressure system may have extended 
farther to the west than indicated.

The cold and dry conditions lasted into the spring, with snow being recorded in Boyle's journal as late as April, although this was only a brief shower on the 9th of the month (NS). While this is unusual, such late occurrences are not without precedent. Rain fell on the 19th April (NS) with showers occurring throughout the remainder of the season, and this broke the drought that had lasted since December 1684. Pleasant, sunny conditions were generally experienced throughout the summer of 1685 although temperatures were likely low compared to modern averages. Autumn of that year was mixed, with several frosts experienced in midto-late September but mostly mild and partly wet conditions were experienced in October and November. In stark contrast to the previous two winters the winter of $1685-6$ was relatively mild with very few frosts and no snow being recorded (Figure 8).

\section{Conclusions}

The weather diary provides a valuable record of weather conditions throughout the year 1685 in London. It seems likely that the data were recorded under the instructions of Robert Boyle as part of the experiments carried out at his laboratory in London. The barometer and thermometer were responsive, well made instruments that provide a detailed picture of the weather for that year, despite uncertainty existing about the nature of the instruments or their recording situation. Unfortunately the pressure data are not able to provide an extension to the London pressure series — which begins in 1692 with the corrected readings taken from John Locke's weather diary (Cornes et al., 2012a) — due to an absence of data for 1686-91. Nonetheless, the readings remain valuable in providing a twice-daily record of the weather for a year during the Late Maunder Minimum (LMM) when there are precious few surviving instrumental weather diaries. A transcription of the diary and the corrected data are available from Cornes (2019).

The most prominent feature of the weather during the year 1685 in London was the drought that lasted into the spring. While the winter of $1684-5$ was cold it was by no means as severe as the previous winter of $1683-4$. The winter of $1685-6$ in contrast was relatively mild. This supports the view put forward by previous researchers (e.g. Lamb, 1995; Mellado-Cano et al., 2018) that while atmospheric blocking and the incidental increase in the degree of meridional 


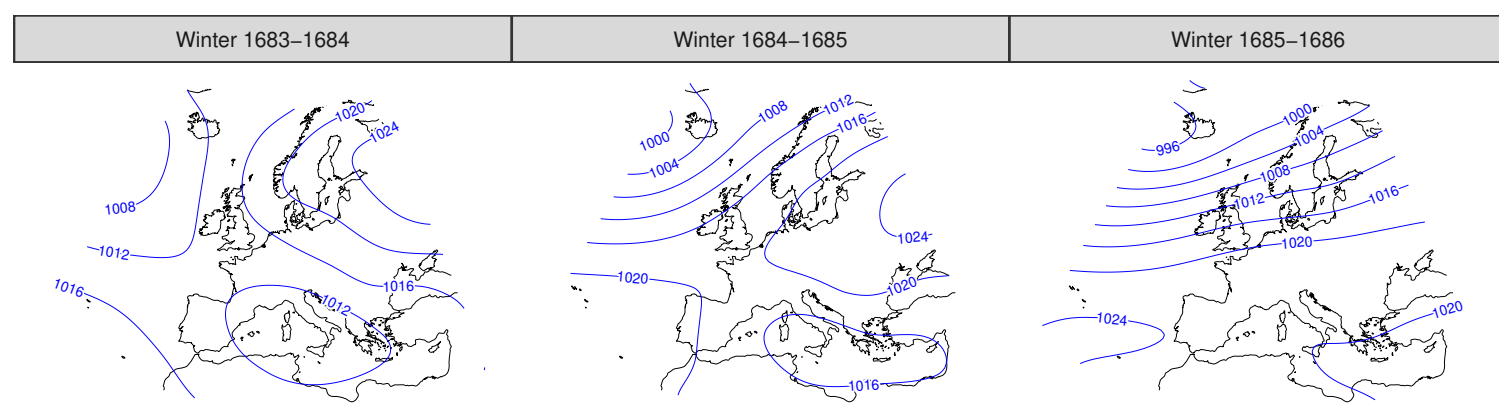

Figure 7: Maps of average MSLP across Europe for the winters of 1683-4 to 1685-6 calculated from the Luterbacher et al. (2002) reconstruction. A variety of proxy data and instrumental observations from across Europe are used in this reconstruction, including Louis Morin's pressure data and the CET data; Boyle's observations are not used. The $5^{\circ}$ longitude/latitude data have been smoothed with a thin-plate spline to produce these maps.

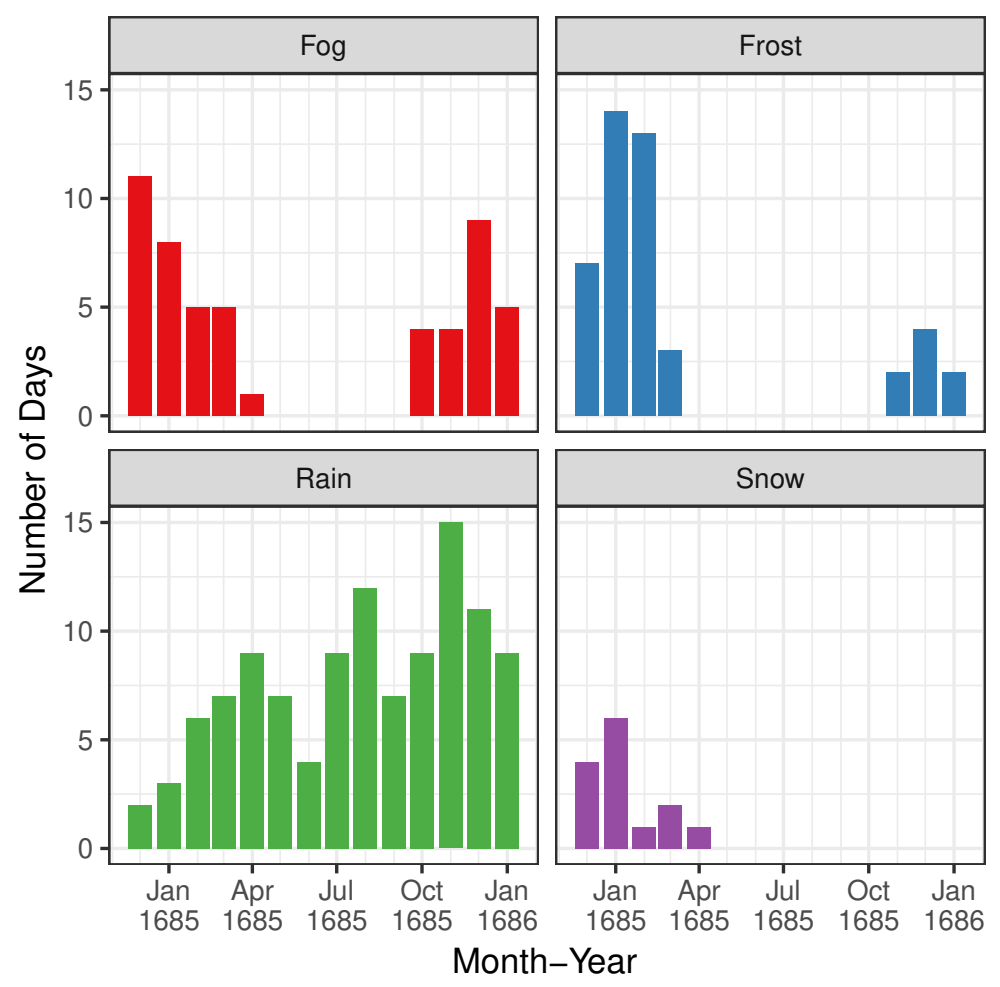

Figure 8: The frequency of four weather types per month. Values are counted if they occurred at least once in the weather description for a given day. February 1686 has been omitted due to the limited number of readings. 
flow were a recurrent feature of conditions during the LMM - particularly during the winter season - this does not apply to all years or indeed to all seasons during the period.

\section{Acknowledgements}

The data for Heathrow Airport were obtained from the British Atmospheric Data Centre's MIDAS repository and the Montsouris data were obtained from the European Climate Assessment and Dataset (https://www.ecad.eu/) repository. The lunar eclipse information was provided by Fred Espenak (NASA's GSFC), and was taken from http://eclipse.gsfc.nasa . gov/lunar.html. Thanks are extended to the Royal Society for permission to reproduce the image of the weather diary used in Figure 2. The anonymous reviewers are thanked for their helpful suggestions.

\section{References}

Bergström, H. and Moberg, A. (2002). Daily air temperature and pressure series for $\{\mathrm{U}\}$ ppsala (1722-1998). Clim. Change, 53:213-252.

Birch, T. (1756). The history of the Royal Society of London for improving of natural knowledge from its first rise, in which the most considerable of those papers communicated to the Society, which have hitherto not been published, are inserted as a supplement to the Phil. Printed for A. Millar.

Boyle, M. (1665a). Some Observations and Directions about the Barometer, Communicated by the Same Hand, to the Author of This Tract. Philos. Trans., 1(1-22):181-185.

Boyle, R. (1665b). New Experiments and Observations Touching Cold, Or an Experimental History of Cold, Begun. To which are Added an Examen of Antiperistatis and an Examen of Mr. Hobs's Doctrine Aubout Cold: Whereunto is Annexed an Account of Freezing Brought in to the Royal. John Crook.

Boyle, R. (1683). New Experiments and Observations Touching Cold. Richard Davis, London.

Boyle, R. (1692). The general history of the air designed and begun by the Honourable. Robert Boyle Esq. Printed for Awnsham and John Churchill. 
Camuffo, D. and Bertolin, C. (2012a). The earliest spirit-in-glass thermometer and a comparison between the earliest CET and Italian observations. Weather, 67(8):206-209.

Camuffo, D. and Bertolin, C. (2012b). The earliest temperature observations in the world: the Medici Network (1654-1670). Clim. Change, 111(2):335-363, doi:10.1007/s10584-011$0142-5$.

Camuffo, D., Bertolin, C., Jones, P. D., Cornes, R., and Garnier, E. (2010). The earliest daily barometric pressure readings in Italy: Pisa ad 1657-1658 and Modena ad 1694, and the weather over Europe. Holocene, 20(3):337-349, doi:10.1177/0959683609351900.

Camuffo, D. and Jones, P. (2002). Improved Understanding of Past Climatic Variability from Early Daily European Instrumental Sources. Kluwer Academic Publishers.

Camuffo, D. and Valle, A. d. (2016). A summer temperature bias in early alcohol thermometers. Climatic Change, 138(3-4):633-640, doi:10.1007/s10584-016-1760-8.

Cornes, R. (2019). A transcription of robert boyle's weather diary 1684-6.

Cornes, R. C., Jones, P. D., Briffa, K. R., and Osborn, T. J. (2012a). A daily series of mean sealevel pressure for London, 1692-2007. Int. J. Climatol., 32(5):641-656, doi:10.1002/joc.2301.

Cornes, R. C., Jones, P. D., Briffa, K. R., and Osborn, T. J. (2012b). A daily series of mean sealevel pressure for Paris, 1670-2007. Int. J. Climatol., 32(8):1135-1150, doi:10.1002/joc.2349.

Crewe, M. (2003). The fathers of scientific meteorology - Boyle, Wren, Hooke and Halley: Part 1. Weather, 58(3):103-107, doi:10.1256/wea.95.02A.

Folland, C. K. and Wales-Smith, B. G. (1977). Richard Towneley and 300 Years of Regular Rainfall Measurement. Weather, 32(12):438-445.

Glaser, R. (2013). Klimageschichte Mitteleuropas: 1200 Jahre Wetter, Klima, Katastrophen : [mit Prognosen für das 21. Jahrhundert]. Primus.

Golinski, J. (2007). British Weather and the Climate of Enlightenment. The University of Chicago Press, Chicago and London.

Goodison, N. (1977). English barometers 1680-1860. 
Gunther, R. T. (1923). Early Science in Oxford, Vol 1: Chemistry, Mathematics, Physics 63 Surveying.

Hall, M. B. (1958). Robert Boyle and Seventeenth-century Chemistry. University Press.

Hughes, R. N. (1984). the Weather Diary of Sir John Wittewronge At Rothamsted, Hertfordshire, 1684???1689. Weather, 39(3):68-78, doi:10.1002/j.1477-8696.1984.tb05463.x.

Hunter, M. (2000). Robert Boyle, 1627-91 : scrupulosity and science. Boydell Press, Woodbridge England Rochester, NY.

Hunter, M. C. W. (2009). Boyle: Between God and Science. Yale University Press.

Hunter, M. C. W. and Davis, E. B. (2007). The Boyle papers: understanding the manuscripts of Robert Boyle. Ashgate Publishing, Ltd.

Jankovic, V. (2001). Reading the Skies: A Cultural History of English Weather, 1650-1820. The University of Chicago Press.

Kington, J. (2010). Collins New Naturalist Library: British Climate and Weather. HarperCollins UK.

Knowles Middleton, W. E. (1964). The History of the Barometer. Johns Hopkins Press, Baltimore, Maryland.

Knowles Middleton, W. E. (1966). A history of the thermometer. Johns Hopkins Press, Baltimore, Maryland.

Lamb, H. H. (1995). Climate, history and the modern world. Routledge, 2nd editio edition.

Legrand, J.-P. and Le Goff, M. (1987). Louis Morin et les observations meteorologiques sous Louis XIV. Comptes Rendus, Série Générale, 4:251-281.

Legrand, J.-P. and Le Goff, M. (1992). Les observations météorologiques de Louis Morin. Direction de la Météorologie Nationale, Ministère de l'Equipment, de Logement et des Transports, monographie No. 6, vol.1.

Luterbacher, J., Xoplaki, E., Dietrich, D., Rickli, R., Jacobeit, J., Beck, C., Gyalistras, D., Schmutz, C., Wanner, H., Luterbacher, Xoplaki, Dietrich, D., Rickli, R., Jacobeit, J., Beck, 
Gyalistras, Schmutz, Wanner, Luterbacher, J., Xoplaki, E., Dietrich, D., Rickli, R., Jacobeit, J., Beck, C., Gyalistras, D., and Schmutz, C. (2002). Reconstruction of sea level pressure fields over the Eastern North Atlantic and Europe back to 1500. Clim. Dyn., 18(7):545-561, doi:10.1007/s00382-001-0196-6.

Maddison, R. E. W. (1955). Studies in the Life of Robert Boyle, F.R.S. Part V. Boyle's Operator: Ambrose Godfrey Hanckwitz, F.R.S. Notes Rec. R. Soc. Lond., 11(2):159-188.

Maddison, R. E. W. (1969). The life of the Honourable Robert Boyle. Taylor \& Francis.

Manley, G. (1961). A preliminary note on early meterological observations in the London region, 1680-171, with estimates of the monthly mean temperatures, 1680-1706. Meteorol. Mag., 3(421):303-310.

Manley, G. (1963). Seventeenth-Century London Temperatures: Some Further Experiments. Weather, 18(4):98-105, doi:10.1002/j.1477-8696.1963.tb01981.x.

Manley, G. (1975). 1684: The coldest winter in the English instrumental record. Weather, $30(5): 133-136$.

Mellado-Cano, J., Barriopedro, D., García-Herrera, R., Trigo, R. M., Álvarez-Castro, M. C., Mellado-Cano, J., Barriopedro, D., García-Herrera, R., Trigo, R. M., and Álvarez-Castro, M. C. (2018). Euro-Atlantic Atmospheric Circulation during the Late Maunder Minimum. J. Clim., 31(10):3849-3863, doi:10.1175/JCLI-D-17-0261.1.

Patterson, L. D. (1953). The Royal Society's Standard Thermometer, 1663-1709. Isis, $44(1 / 2): 51-64$.

Pfister, C. (1999). Wetternachhersage: 500 Jahre Klimavariationen und Naturkatastrophen (1496-1995). P. Haupt.

Plot, R. (1685). Observations of the Wind, Weather, and Height of the Mercury inthe Barometer, through out the year 1684; Taken in the Musaeum Ashmoleanum at Oxford, by Robert Plot, LLD. to which is Prefixt a Letter from Him, to Dr. Martin Lister, F. of the R. S. concerni. Philos. Trans., 15(167-178):930-943.

Pribyl, K. and Cornes, R. C. (2019a). Droughts in medieval and early modern england: Part 1. the evidence. Weather, In Review. 
Pribyl, K. and Cornes, R. C. (2019b). Droughts in medieval and early modern england: Part 2.impacts. Weather, In Review.

Shapin, S. (1988). The House of Experiment in Seventeenth-Century England. Isis, 79(3):373404.

Shaw, N. (1920). Pioneers in the science of weather. Q. J. R. Meteorol. Soc., 46(194):141-154, doi:10.1002/qj.49704619403.

Slonosky, V., Jones, P., and Davies, T. (2001). Instrumental pressure observations and atmospheric circulation from the 17th and 18th centuries: London and Paris. Int. J. Climatol., 21(3):285-298, doi:10.1002/joc.611.

Smith, J. (1688). A Compleat Discourse of the Nature, Use, and Right Managing of that Wonderful Instrument, the Baroscope, Or Quick-silver Weather-glass: In IV. Parts. By John Smith, C.M. To which is Added, the True Equation of Natural Days; Drawn Up for the Use of the Gen. Joseph Watts, at the Angel in S. Paul's Church-Yard.

Stevenson, J., Williams, M. H., and Society, H. R. (1999). "Observations of Weather": The Weather Diary of Sir John Wittewronge of Rothamsted 1684-89. Hertfordshire Record Society. 